\title{
O BURITI (TRITHRINAX BRASILIENSIS MART.) NA OBRA DE ANTIGOS CRONISTAS DO RIO GRANDE DO SUL ${ }^{1}$
}

\author{
JOSÉ NEWTON CARDOSO MARCHIORI²
}

\section{RESUMO}

Antes mesmo da descrição botânica, o buriti (Trithrinax brasiliensis Mart.) já constava na literatura de antigos cronistas do Rio Grande do Sul. O presente artigo visa a agregar essas referências dispersas na literatura ao conhecimento botânico.

Palavras-chave: Arecaceae, Buriti, Botânica, Cronistas, Palmeiras, Rio Grande do Sul, Trithrinax brasiliensis Mart., Viajantes.

\section{ABSTRACT}

[The Buriti Palm (Trithrinax brasiliensis Mart.) in the literature of ancient chroniclers of Rio Grande do Sul State, Brazil].

Even prior the botanical description, the Buriti Palm (Trithrinax brasiliensis Mart.) had already appeared in the literature of ancient chroniclers that visited the State of Rio Grande do Sul (Brazil). This article seeks to add these scattered references of the literature to botanical knowledge.

Key words: Arecaceae, Buriti Palm, Botany, Croniclers, Palm trees, Rio Grande do Sul State, Travelers, Trithrinax brasiliensis Mart.

\section{INTRODUÇÃO}

De distribuição neotropical, o gênero Trithrinax foi criado por Martius em 1837, no clássico Historia Naturalis Palmarum, com base em uma exsicata sem número, coletada por Friedrich Sellow no Rio Grande do Sul. Por muitos anos, Trithrinax brasiliensis foi o único binômio em seu gênero botânico.

Em 1878, Carl Georg Oscar Drude descreveu Trithrinax acanthocoma a partir de "uma comunicação pessoal" do botânico e paisagista francês Auguste François Marie Glaziou, de marcante atuação no Rio de Janeiro, que lhe mostrou "essa palmeira ornamental" cultivada na capital do império e em "alguns parques europeus", e cujas "populações naturais" foram referidas para o "sul do Brasil" (Cano et al, 2013, p. 21). Sem definir um espécime tipo em

1 Recebido em 14-5-2014 e aceito para publicação em 17-6-2014.

2 Engenheiro Florestal, Dr. Bolsista de Produtividade em Pesquisa (CNPq - Brasil). Professor Titular do Departamento de Ciências Florestais, Universidade Federal de Santa Maria.marchiori@pq.cnpq.br sua publicação original, Drude completou a descrição na monografia da família vinda a lume em 1882 na Flora Brasiliensis, designando como tipo a coleta $n^{\circ}$ 9.014, de Glaziou, conservada no Museu de História Natural de Paris. Desde então, estes dois binômios têm recebido interpretações diversas na taxonomia botânica.

Em seu estudo sobre as palmeiras do estado de Santa Catarina, Reitz (1974) considerou apenas Trithrinax brasiliensis como espécie nativa. $\mathrm{O}$ autor destacou sua presença mais freqüente em "campos sujos" e na "orla das matas dos pinhais", na região fitogeográfica da "Mata de Araucária e Campos", definindo-a como "elemento raro e estranho" na "Zona da mata pluvial da Encosta Atlântica”, mais especificamente no "Morro dos Conventos", ocorrência para a qual fornece, inclusive, uma foto tomada em 10 de Janeiro de 1957.

Em sua revisão sobre as palmeiras do Rio Grande do Sul, Mattos (1977) apresentou uma nova combinação para Trithrinax acanthocoma, considerando o táxon uma variedade de $T$. brasiliensis. Lorenzi et al. (2004), por sua vez, reduziram Trithrinax acanthocoma à sinonímia 
de T. brasiliensis, e definiram o Planalto Meridional dos três estados sulinos (Paraná, Santa Catarina e Rio Grande do Sul) como a área de ocorrência natural da espécie.

Em publicações mais recentes, Lorenzi et al. (2010) e Soares et al. (2014) consideraram válidos ambos os binômios. Sobre este ponto, todavia, Cano et al. (2013), com base no exame de populações naturais de ambos os taxa, na análise morfológica exaustiva dos espécimes conservados em herbários do Brasil e de outras partes do mundo, inclusive dos respectivos tipos, bem como no emprego de métodos de filogenia molecular, acabaram por reconhecer a existência de duas variedades em Trithrinax brasiliensis: T. brasiliensis var. brasiliensis e T. brasiliensis var. acanthocoma.

Sem qualquer tomada de posição sobre a questão taxonômica acima exposta, o presente trabalho visa, tão simplesmente, a reunir antigas referências sobre o buriti, constantes em obras pouco divulgadas de botânicos, bem como de antigos viajantes, naturalistas e/ou cronistas que percorreram o Rio Grande do Sul a partir do século dezenove. Mesmo sem valor taxonômico, não restam dúvidas sobre a importância do corpus documental presentemente resgatado para o preenchimento de importante lacuna na bibliografia da palmeira em foco.

\section{O BURITI, EM ANTIGOS RELATOS}

$\mathrm{Na}$ literatura de antigos viajantes e cronistas da terra gaúcha, o nome de Auguste de SaintHilaire se destaca não apenas pela alta qualidade textual e diversidade de informações, como, também, por ter sido um dos primeiros botânicos a percorrer a região. É de lastimar-se, portanto, que sua obra não mencione o buriti, fato que se explica, tão somente, pelo fato do autor não ter estudado mais detidamente sua coleta de $n^{\circ}$ 2.764, conservada no Museu de História Natural de Paris, pois, se tal houvesse acontecido, é muito provável que Trithrinax brasiliensis - e o respectivo gênero botânico -, não tardariam mais de quinze anos a serem descritos. Em dois momentos anteriores, pelo menos, Saint-
Hilaire esteve próximo a populações de Trithrinax brasiliensis, mas sem chegar a conhecê-las, não custa repetir, e por motivos distintos.

Antes mesmo de entrar na "Província do Rio Grande de São Pedro do Sul", o viajante atravessou o rio Araranguá quando já era escuro, motivo pelo qual não pode alcançar o lugar previsto para pouso. "Quando o dia amanheceu", ele deu-se conta de que passara a noite "num lugar muito aprazível", em uma "uma clareira coberta de relva, ao lado de uma lagoa (...) cercada de morros escarpados de diferentes formas, vendo-se num deles alguns casebres". De acordo com as palavras do viajante, mal ele deixou "esse encantador lugar", viu-se de novo "na praia" de "areias brancacentas", com o mar "bramindo incessantemente" e sem "nenhuma vegetação". ${ }^{3}$

O texto de Saint-Hilaire não deixa margem a dúvidas: ele passou aquela noite na região de Morros dos Conventos e, se tivesse investigado a vegetação local na manhã seguinte, não deixaria de encontrar, certamente, as palmeiras que ali ainda existem, e cujo registro fotográfico consta em obra de Raulino Reitz. ${ }^{4}$ Cabe salientar que o botânico não menciona a espécie nos morros de Torres, por ele detidamente investigados, nem mesmo na região de Itapeva, por ele visitada a 7 de junho de 1820 , e da qual procedem coletas de Trithrinax brasiliensis var. acanthocoma, segundo Cano et al. (2013). Em Itapeva, aliás, o francês percorreu "cerca de três quartos de légua de praia", e seguiu por uma "grande planície úmida, revestida de espessa erva disposta em tufos", na qual se percebiam,

\footnotetext{
SAINT-HILAIRE, A. de. Viagem a Curitiba e província de Santa Catarina. Belo Horizonte: Editora Itatiaia, 1978. p. 208.

4 Sob o nome de "carandá", o botânico catarinense publicou uma foto do grupo de indivíduos de Trithrinax brasiliensis var. acanthocoma (sensu Cano et al., 2013) existente no "Morro dos Conventos", município de Araranguá, tomada a 10 de Janeiro de 1957 (REITZ, R. Palmeiras. In: REITZ, R. Flora Ilustrada Catarinense. Itajaí: Herbário Barbosa Rodrigues, 1974. p. 10).
} 
“aqui e ali, pequeninos capões". De acordo com as palavras do viajante, a "monotonia da paisagem" somente era quebrada pela "grande cordilheira" existente a oeste da planície percorrida, acrescentando que havia "áreas consideráveis" com "butiás" para o "lado da serra". Da relva seca pelo sol do verão, o autor coletou o Eriocaulon $\mathrm{n}^{\circ} 1.805$, o qual, pela baixa numeração, exclui a possibilidade de ele haver coletado em Itapeva a exsicata $\mathrm{n}^{\circ} 2.764$, anteriormente comentada. Os indivíduos existentes na região, além disso, são de Trithrinax brasiliensis var. acanthocoma, distintamente da exsicata de Saint-Hilaire, conservada no Museu de Paris.

Seguindo pelo litoral, o francês alcançou Viamão e Porto Alegre, partindo em seguida na comitiva do governador da capitania ${ }^{5}$ para São José do Norte e Rio Grande, através da península situada entre a laguna dos Patos e o oceano Atlântico. Em todo esse percurso, bem como no trecho de Rio Grande até a divisa com o Uruguai, no Chuí, o viajante seguiu pela planície litorânea, motivo pelo qual se pode descartar a possibilidade de Saint-Hilaire haver encontrado o buriti neste percurso. Ao retornar à província pelo atual município de Barra do Quaraí, ele encaminhou-se às antigas Missões Jesuíticas, passando por Santa Maria em seu retorno a Porto Alegre.

Foi ainda no Planalto Médio, antes de descer para a Depressão Central, que Saint-Hilaire colheu o material de Trithrinax brasiliensis em questão, de acordo com indícios constantes no livro de viagens e a sequência numérica de suas exsicatas.

Escrito "às margens do Itapiru-Guaçu", o texto de 28 de Março de 1821 registra a observação de "uma planta semelhante à palmeira", a "quarta" encontrada pelo viajante no Brasil ${ }^{6}$.

\footnotetext{
5 Nobre português $\left(1^{\circ}\right.$ Conde da Figueira), o General José Maria Rita de Castelo Branco governou a capitania de São Pedro do Rio Grande do Sul de 1818 a 1821.

6 SAINT-HILAIRE, A. de. Viagem ao Rio Grande do Sul. Porto Alegre: Estante Rio-Grandense União de Seguros; ERUS; Martins Livreiro, 1987. p. 386.
}

Embora apontando mais para a tuvarana (Cordyline spectabilis Kunth \& Bouché), planta abundante no primeiro e segundo planaltos do Paraná, por ele anteriormente atravessados, e cujo estipe lembra, efetivamente, o de uma pequena palmeira, não se pode descartar que se trate de uma referência velada ao buriti, uma vez que na "estância de Tupaceretã", tratada na sequência, o autor coletou, entre outras plantas,

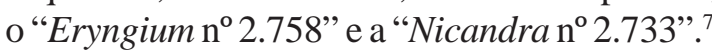
A sua amostra $n^{\circ} 2.764$ (de Trithrinax brasiliensis), distante apenas seis números do referido Eryngium, permite essa especulação, até mesmo por que as citações de eventuais plantas na "Viagem" de Saint-Hilaire não seguem, rigorosamente, a ordem de coleta, como visto na frase anterior ${ }^{8}$. De todo o modo, se não foi às margens do Itapiru-Guaçu, a coleta do buriti foi realizada em local não muito distante, nas estâncias "de "Tupaceretã", de "Santiago" e "Salvador Lopes", ou então na "entrada do mato". 9 Todas estas antigas referências geográficas se encontram na região do Planalto Médio compreendida entre os rios Jaguari e Toropi, uma vez que o viajante desceu a serra pela "Picada de São Tiago", constante em relatos de antigos cronistas do período jesuítico (Marchiori \& Alves, 2011).

Cabe salientar, ainda, que Saint-Hilaire não chegou a conhecer o palmar de buritis e butiás ${ }^{10}$ existente no curso médio do rio Toropi, nos confins dos atuais municípios de Júlio de Castilhos, Quevedos e São Martinho da Serra, pois ele não deixaria de mencionar, certamente, uma vegetação tão invulgar e de extraordinária beleza. Situado a leste da rota por ele utilizada, o viajante seguiu pela região da extinta capela

\footnotetext{
SAINT-HILAIRE, 1987. Op. cit., p. 322.

8 Saint-Hilaire, como se vê, cita por primeiro o Eryngium $\left(\mathrm{n}^{\circ} 2.758\right)$ e depois a Nicandra $\left(\mathrm{n}^{\circ} 2.733\right)$, que o antecede em 25 números, na sequência de coletas.

9 SAINT-HILAIRE, 1987. Op. cit., p. 322-325.

${ }^{10}$ Trata-se de Butia witeckii K. Soares \& S. Longhi, espécie recentemente descrita (SOARES, K.; LONGHI, S.J. Uma nova espécie de Butia (Becc.) Becc. (Arecaceae) para o Rio Grande do Sul, Brasil. Ciência Florestal, Santa Maria, v. 21, n. 2, p. 203-208, 2011).
} 
jesuítica de Santiago, por ele descrita como "estância", e de cujo antigo dono derivaria o nome ${ }^{11}$. Seguindo pelo planalto compreendido entre os rios Toropi e Jaguari, Saint-Hilaire alcançou a Depressão Central após cruzar pelo "Toropi-Chico", em ponto não distante de sua foz no "Toropi-Grande". ${ }^{12}$

$\mathrm{Na}$ literatura sul-rio-grandense, a referência literária mais antiga ao buriti é a que se encontra, provavelmente, em texto manuscrito ainda inédito de Friedrich Sellow, naturalista que percorreu a província de São Pedro logo após SaintHilaire, nos anos de 1823 a 1827. Morto em outubro de 1831 por afogamento nas águas do rio Doce, em Minas Gerais, esse prussiano não viveu o suficiente para publicar relatos de viagem, bem como os trabalhos científicos que lhe trariam merecida fama na literatura botânica. Mesmo assim, cabe-lhe o reconhecimento da posteridade como coletor de plantas mais citado na monumental "Flora Brasiliensis". Dos textos por ele deixados, salienta-se uma carta de 28 páginas, endereçada ao Barão de Altenstein $^{13}$, em que relata a viagem realizada

${ }^{11}$ Equívoco de Saint-Hilaire: muito antigo, o nome deriva da Capela Jesuítica de Santiago, constante em autores como Henis (1970) e Saldanha (1938), cronistas dos primórdios da história sulina.

12 A 31 de Março, Saint-Hilaire redigiu seu diário na "Estância de Salvador Lopes"; a $1^{\circ}$ de Abril, ele se encontrava na "entrada do mato"; no dia 2 de Abril, as anotações referem-se a "São Xavier", distante 2 léguas e meia do pouso anterior; em 3 de Abril, ele já estava no "ToropiChico, após 2 léguas e meia de percurso; e a 4 de Abril nas margens do "Toropi-Grande", distante légua e meia do "Toropi-Chico" (SAINT-HILAIRE, 1987. Op. cit., p. 323-328).

${ }^{13}$ Karl Sigmund Franz Freiherr von Stein zum Altenstein (1-X-1770 - 14-V-1840); primeiro ministro da Cultura no reino da Prússia, responsável pela reforma de seu sistema educacional. Era por sua intermediação, principalmente, que Friedrich Sellow devia o necessário apoio financeiro para as excursões pelo interior do Brasil e a província Cisplatina (atual Uruguai), motivo pelo qual enviava relatórios, dos quais procedem os trechos aqui transcritos. A respeito do texto consultado, ele resulta de tradução do General Bertholdo Klinger (1884-1969) ainda não publicada, redigida de acordo com sua curiosa "Ortografia Simplificada Brazileira”, não reproduzida no presente artigo, cumpre salientar. nos anos de 1823 e 1824 à Serra do Sudeste com o objetivo principal de coletar amostras de rochas, além de obter informações sobre a presença de ouro na região de Caçapava e sobre uma mina de prata que, desde o tempo dos jesuítas, dizia-se haver na região de Aceguá, atual fronteira com o Uruguai. Depois de passar pela "freguesia de Caçapava", localidade de uns "cem fogos", situada em "cumeada granítica", o viajante observou os primeiros buritis, descritos como "Coryphas", no alto de paredões e montanhas escarpadas:

O sopé e o topo são revestidos de relva e adornados de uma Corypha, cujo estipe atinge, no máximo, duas a três braças, e aparece isolada ou em grupos de três ou quatro. Nas fendas e gargantas crescem gramíneas, do meio das quais a palmeira gerivá ergue sua copa em forma de espanador de penas (...).

Para o bom entendimento do fragmento transcrito, cabe lembrar que a medida indicada corresponde a 2,2 metros, o que leva a estimar os indivíduos entre 4,4 e 6,6 metros de altura, dimensões condizentes à espécie em questão.

A respeito do nome atribuído (Corypha), trata-se de identificação realizada a campo, sem auxilio de qualquer tipo de bibliografia. Sobre este ponto, vale lembrar que o gênero Trithrinax foi descrito por Friedrich Martius somente em 1837, e com base em material botânico coletado por Sellow, provavelmente nessa viagem. ${ }^{14}$ Até hoje, na impossibilidade da identificação segura no momento de coleta, é costume anotar-se "nomes-fantasia" para materiais desconhecidos, com o objetivo de facilitar a memo-

\footnotetext{
${ }^{14}$ Tendo-se em vista que o Holótipo de Trithrinax brasiliensis não informa o número e data de coleta, constando apenas "Rio Grande do Sul", o local do evento torna-se objeto de mera especulação. Embora mais freqüente na Serra do Sudeste, não se descarta a possibilidade de Friedrich Sellow ter realizado a coleta original na viagem de Santa Maria a São Martinho, antes mesmo de sua primeira ida à capital da província, uma vez que a espécie ainda hoje se encontra na região de Santo Antão (Santa Maria), no topo de morros.
} 
rização de aspectos relativos ao indivíduo. De todo modo, não resulta descabida a aplicação deste nome genérico relativo à flora asiática (Corypha L.), uma vez que a palmeira sul-riograndense, única espécie de folhas palmadoflabeliformes da flora regional, pertence, efetivamente, à subfamília Coryphoideae.

Depois de Caçapava, Friedrich Sellow encaminhou-se para a "serra de Barbaraquá", "onde ficam as principais nascentes do Camaquã do Salso, Vacacaí e Jaguari”, região por ele considerada "a mais alta da província" 15 e capaz de "fornecer excelentes espécimes de plantas". Descendo pelo "Camaquã abaixo", o prussiano encontrou, no "Passo dos Enforcados", "grupos de montes esferóides" que lhe pareceram "ruínas de altas fortalezas" quando vistas de longe, e que eram coroadas, no topo, de "mimosas arbustivas, mirtáceas, (...) às vezes, ainda, coryphas".

Sempre exatas, as referências geográficas e botânicas do incansável viajante comprovam, efetivamente, as suas andanças pela região. A alta serra do Baberaquá, por vezes grafada Barbaraquá, Babiraquá ou Baebera-cuá, situase no limite dos atuais municípios de Lavras do Sul e São Gabriel ${ }^{16}$, servindo de nascente, conforme registro preciso de Sellow, para tributários de três importantes bacias hidrográficas: o rio Vacacaí, que encaminha suas águas para o Jacuí e lago Guaíba; o Jaguari ou Pirajacã, tributário dos rios Santa Maria, Ibicuí e Uruguai; e de um dos braços do Camaquã, que lança suas águas na laguna dos Patos. "Enforcados", por sua vez, é nome de antigo passo do rio Camaquã, no município de Bagé. ${ }^{17}$ A respeito dos "montes esferóides" com aspecto de "altas fortalezas", a descrição se ajusta, com perfeição, à geomorfologia do "Rincão do Inferno", das

${ }^{15}$ Com alguns pontos em altitude superior a $430 \mathrm{~m}$, a serra de Baberaquá é a mais alta da metade sul do estado do Rio Grande do Sul.

${ }^{16}$ FARIA, O. A. de. Diccionário Geográphico, Histórico e Estatístico do Estado do Rio Grande do Sul. Porto Alegre: Livraria do Globo, 1914. p. 194.

${ }^{17}$ FARIA, O.A. de, 1914. Op. cit., p. 134.
"Guaritas" e/ou da "Casa de Pedra", inclusive pela referência a mimosas espinhosas ${ }^{18}$, a mirtáceas anãs ${ }^{19}$ e ao buriti, dito "Corypha" pelo viajante.

$\mathrm{Na}$ busca de registros histórico-literários sobre o buriti, não se poderia passar ao largo do nome prestigioso de Aimé Bonpland - e não apenas por sua residência na gaúcha São Borja a partir de 14 de Fevereiro de 1931,20 - mas, sobretudo, pelo relato de uma longa travessia em direção à capital da província, realizada nos anos de 1849 e 1850 . Com transcrição e notas de Alicia Lourteig"21 " "Voyage de Sn. Borja a la cierra y a Porto Alegre" veio a lume em 1978, em coedição do Instituto de Biociências da UFRGS e o "Centre Nationale de la Recherche Scientifique". ${ }^{22}$

Personalidade singular, sob muitos pontos de vista, o botânico francês ainda está à espera de um biógrafo capaz de retratá-lo em suas múltiplas facetas. ${ }^{23}$ Embora secundário ao tema em análise, convém levantar alguns pontos da biografia de Bonpland, na (vã) tentativa de justificar ou compreender sua longa permanência na região do Prata, em locais distantes da alta cultura e do mundo científico a que estava acostumado na Europa, para levar uma vida de muita

${ }^{18}$ Na situação descrita, são especialmente abundantes: Mimosa trachycarpa Benth. e Mimosa ramulosa Benth.

${ }^{19}$ Caso de Campomanesia aurea O. Berg, entre outras espécies.

${ }^{20}$ BELL, S. A life in shadow. Aimé Bonpland in southern South America, 1817-1858. Stanford: Stanford University Press, 2010. p. 89.

${ }^{21}$ Renomada botânica argentina (1913-2003), vinculada ao "Instituto Miguel Lillo" (Tucumán, Argentina), ao Darwinion (San Isidro, Pcia. de Buenos Aires) e, após 1955, ao "Laboratoire de Fanérogamie", do Museu Nacional de História Natural da França, em Paris.

22 BONPLAND, A. Journal Voyage de Sn. Borja a la Cierra y a Porto Alegre. Porto Alegre: Instituto de Biociências, Departamento de Botânica; Paris: Centre Nationale de la Recherche Scientifique, 1978. 175p.

${ }^{23}$ Como primeira aproximação à vida e obra do autor, recomenda-se o romance "Figura na Sombra", de Luiz Antonio de Assis Brasil (2012), sobretudo por ser obra em português, de fácil acesso e agradável leitura, ressaltando-se, todavia, o seu viés nitidamente ficcional. 
atividade e compromissos materiais, embora marcada por desventuras, pela solidão intelectual e pela pobreza ${ }^{24}$.

Bonpland chegou a Buenos Aires em Janeiro de 1817, atraído pelos projetos da criação de um Jardim Botânico e de um Museu de História Natural na cidade. Frustradas as expectativas, partiu para as selvas da atual província de Misiones em 1820, dando início à exploração da erva-mate nos arredores do povoado de Santa Anna de los Guácaras, antiga redução jesuítica. Tratado como espião, foi feito prisioneiro por ordem de Francia ${ }^{25}$, e retido na aldeia paraguaia de Santa Maria da Fé por quase dez anos. Após a libertação, decidiu instalar-se em São Borja, passando a trabalhar como médico, na criação de gado e, com muito afinco, no cultivo e exploração da erva-mate. Foi nessa etapa da vida que aconteceu a viagem de São Borja a Porto Alegre, iniciada a 11 de fevereiro de 1849, e com o objetivo principal de conduzir uma tropa de ovelhas de fina lã para venda ao Sr. Antonio Rodrigues Chaves ${ }^{26}$, proprietário da estância Santa Cruz, situada em área próxima à atual cidade gaúcha de mesmo nome. Outra meta era investigar a presença da erva-mate na floresta do rebordo do Planalto Meridional, e avaliar a conveniência de estabelecer uma plantação da espécie na região. Por fim, a viagem poderia viabilizar o envio do "certificat de vie" em Porto Alegre, documento necessário para receber

${ }^{24}$ Aimé Bonpland faleceu em sua "estancia de Santa Anna", na província argentina de Corrientes, e foi sepultado no cemitério da Santa Cruz, em Restauración (atual Paso de los Libres).

25 José Gaspar Rodríguez de Francia (1776-1840). Doutor em Teologia (Universidad de Córdoba, Argentina), revolucionário e político paraguaio, nomeado "Ditador Perpétuo da República do Paraguai" a partir de 1816. Outro cognome associado ao ditador é o de "El Supremo", título dado à obra biográfica escrita pelo eminente intelectual e historiador paraguaio Augusto Roa Bastos (1917-2005).

${ }^{26}$ Pedro Rodrigues Fernandes Chaves (1810-1866), filho do Barão de Quaraí, magistrado, jornalista e político brasileiro, proprietário da estância Santa Cruz, no então município de Rio Pardo. os semestres atrasados da "pensão" que lhe fora concedida pelo governo francês.

A partir da estância Santa Cruz, Bonpland aproveitou o tempo que dispunha até o fechamento do negócio para investigar a vegetação da "Cerra", constando, em seus apontamentos, uma possível menção ao objeto em estudo:

Dans le cours de cette journée j'ai vu un palmier nouveau pour moi, deux espèces de tradescantia ${ }^{27}$, une justicia ${ }^{28}$, le palo de leche $^{29}$ et un grand nombre de plantes qui me sont inconnues. ${ }^{30}$

No texto do viajante francês, o que chama atenção é a referência a "uma espécie de palmeira" por ele desconhecida, a qual poderia tratar-se, em princípio, tanto do buriti como do palmiteiro, uma vez que ambas as espécies são nativas na região em foco. Embora mais raro, o buriti ainda se encontra em muitos pontos no rebordo do Planalto Meridional, havendo na literatura, inclusive, um artigo recente sobre população autóctone no vale do rio Pardo $^{31}$, em área próxima à investigada por Bonpland no ano de 1848. No caso do palmiteiro (Euterpe edulis Mart.), a espécie é de ocorrência freqüente no sub-bosque das matas da região, sobretudo em locais de menor altitude. Esta última alternativa parece a mais provável, posto que Bonpland conhecia populações de Trithrinax campestris

${ }^{27}$ Referência a uma espécie do gênero Tradescantia L. (Commelinaceae).

${ }^{28}$ Referência a uma espécie do gênero Justicia L. (Acanthaceae).

${ }^{29}$ Trata-se do leiteiro ou pau-de-leite, Sapium glandulosum (L.) Morong, Euforbiácea de ampla distribuição nas florestas do Rio Grande do Sul.

${ }^{30}$ Tradução: No curso desta excursão eu vi uma palmeira nova para mim, duas espécies de tradescantia, uma justicia, o pau-de-leite e um grande número de plantas que me eram desconhecidas (BONPLAND, 1978. Op. cit., p. 40).

${ }^{31}$ SÜHS, R.B.; PUTZKE, J. Nota sobre a ocorrência de uma população de Trithrinax brasiliensis Martius (Arecaceae) no vale do rio Pardo, Rio Grande do Sul, Brasil. Pesquisas, Botânica, São Leopoldo, n. 61, p. 330332, 2010. 
(Burmeist.) Drude \& Griseb. na região da Mesopotâmia argentina ${ }^{32}$, espécie por ele chamada, provisoriamente, de "Palma de Sombrero". ${ }^{33}$

Dez anos mais tarde (1858), foi Robert AvéLallemant que atravessou a província, mas em sentido inverso ao de Bonpland, movido pelo desejo de conhecer pessoalmente o famoso botânico francês. Não o encontrando em São Borja, esse médico de acentuado pendor para as ciências naturais, e que trabalhara por muitos anos no Rio de Janeiro, encaminhou-se a Uruguaiana e à província argentina de Corrientes, encontrando o francês em sua estância de Santa Anna, ao sul de Restauración (atual Paso de los Libres). Avé-Lallemant, aliás, foi provavelmente o último europeu a apertar a mão do velho amigo de Humboldt, uma vez que ele veio a falecer poucos dias após a visita, a 4 de Maio de 1858.

No retorno a Porto Alegre, via Alegrete, São Gabriel e Caçapava, os primeiros buritis foram registrados por Avé-Lallemant entre as duas últimas localidades, após haver deixado a estância do "Comendador Cruz Jobim", o Barão de Cambai. ${ }^{34} \mathrm{O}$ viajante relata que a paisagem tornou-se "alcantilada", com montanhas cobertas de relva e "múltiplos desfiladeiros e vales" en-

32 BONPLAND, A. Archives inédites. Buenos Aires: Jacobo Peuser, 1924. Tomo 2. s.p.

${ }^{33}$ Constante na última folha do v. 2 de seus "Archives Inédites" (BONPLAND, 1924. Op. cit., s.p.), antecedida, apenas, da "Table" (Sumário), Bonpland anotou para essa palmeira: "foliis palmatis" e "faire de chapeaux".

${ }^{34}$ José Martins da Cruz, que acresceu a seu nome o de "Jobim" por ter o seu pai nascido na vila homônima, na região do Douro, Portugal. CARVALHO (1937, p. 5051) informa que o Barão de Cambaí era "senhor de avultados bens de fortuna" e "contribuiu, largamente, para a Campanha do Paraguai". Robert Avé-Lallemant acrescenta que o Barão de Cambai era irmão do "Senador Jobim” (José Martins da Cruz Jobim, 1802-1878), decano da Faculdade de Medicina do Rio de Janeiro e seu conhecido desde o tempo em que trabalhou na Santa Casa de Misericórdia, na capital do império. Os barões de Cambaí não deixaram descendência e foram padrinhos de batismo do político gaúcho Joaquim Francisco de Assis Brasil. Resta informar que Maria Joaquina, uma meia-irmã do Barão de Cambaí, foi bisavó do famoso maestro Tom Jobim. tre as mesmas, lembrando-lhe os arredores de Jena, Alemanha. Foi nessa situação que ele encontrou os primeiros grupos de buritis em "depressões protegidas", "às margens de riachos". ${ }^{35}$ No retrospecto de sua "peregrinação pela Província", o viajante fornece mais informações sobre a árvore:

Em geral várias delas formavam um pequeno palmar, que se elevava muito acima do mato baixo. O buritizeiro, uma Mauritia de frutos comestíveis e seiva potável, uma espécie de vinho de palma, sempre me causou particular impressão. Crescendo, em regra, em lugares pantanosos, em margens de riachos, é o estipe regularmente muito mais delgado em baixo do que em cima, com proporcionado e gradual intumescimento. Poucas folhas flabeliformes formam a fronde, para cuja insignificância o alto tronco parece ser um verdadeiro luxo. Com a forma delgada do tronco sobre as raízes e com o intumescimento até ao dobro da grossura no alto, parece que a árvore vai cair com a primeira tempestade, tanto mais quando o buritizeiro não costuma crescer entre outras árvores que possam protegê-lo e apoiá-lo. Mas, apesar da forma anormal e da considerável altura, resiste firme. ${ }^{36}$

Não restam dúvidas acerca da identidade da palmeira a que se refere Robert Avé-Lallemant: em vez uma Mauritia, gênero conspícuo na vegetação do centro-norte do Brasil, e com o qual comparte o mesmo nome comum, além da presença de folhas palmado-flabeliformes, o que o viajante encontrou na região de Caçapava foram indivíduos de Trithrinax brasiliensis Mart., a única espécie desse gênero botânico, que é nativa na Serra do Sudeste gaúcho. De presença frequiente, em 1858, o buriti é uma das palmeiras atualmente mais ameaçadas de extinção,

\footnotetext{
${ }_{35}$ AVÉ-LALlEMANT, R. Viagem pela Província do Rio Grande do Sul no ano de 1858. Rio de Janeiro: Ministério da Educação e Cultura, 1953. p. 311-312.

${ }^{36}$ AVÉ-LALLLEMANT, 1953. Op. cit., p. 340.
} 
restando poucos indivíduos ou agrupamentos na metade sul do estado. A natural fragilidade das árvores, salientada pelo viajante, juntamente com a mortalidade natural, a prática de queimadas, bem como o pisoteio e a predação de brotações, exercidos pelo gado, são alguns dos motivos que explicam a rarefação gradativa da espécie. É por este motivo, entre outros, que não se justifica o projeto de implantação de usinas hidrelétricas no curso médio do rio Toropi, sobretudo nas proximidades da foz do Guassupi $\left(29^{\circ} 24^{\prime} 15,57^{\prime \prime} \mathrm{N}-54^{\circ} 01^{\prime} 33,39^{\prime \prime} \mathrm{S}\right)$, nos confins dos municípios de Júlio de Castilhos, São Martinho da Serra e Quevedos, uma vez que é nessa área que se encontra o último palmar significativo de Trithrinax brasiliensis, além de outros numerosos endemismos. Resta comentar que a referência à "seiva potável", "uma espécie de vinho de palma", não se confirma na literatura sobre a espécie gaúcha, devendo-se, provavelmente, à confusão feita pelo viajante com Mauritia flexuosa L. f., espécie de vasta dispersão no centro e norte do Brasil.

Em 1868, dez anos após a viagem de AvéLallemant, chegava outro culto alemão ao Rio Grande do Sul, e que também deixou referências sobre o buriti. Diplomado pela Faculdade Politécnica de Dresden, e com aperfeiçoamento na Universidade de Halle, Max Beschoren (1847-1887) trabalhou como agrimensor em diversas colônias no estado. Foi em trabalhos de demarcação de terras que esse abnegado homem de ação chegou a conhecer o interior do estado como poucos em sua época, e passou a contribuir com magníficas cartas de viagem, recheadas de valiosas informações científicas, vindas a lume no "Deutsche Zeitung", de Porto Alegre. ${ }^{37}$

Encarregado de triangular as terras de Nonoai, Peperi e Chapecó, ao norte de Passo

\footnotetext{
${ }^{37}$ Periódico em língua alemã, editado em Porto Alegre no período de agosto de 1861 até a entrada do Brasil na Primeira Guerra Mundial (1917). Carlos von Koseritz (1830-1890), seu mais famoso editor, imprimiu forte tendência germânica e anticatólica ao jornal.
}

Fundo e Palmeira das Missões, Beschoren foi um dos primeiros "homens brancos" a adentrar em muitos pontos do Alto Uruguai, produzindo um valioso material cartográfico e geodésico, bem como preciosos registros sobre a vegetação, condições geológicas, meteorologia, dados etnológicos e história regional, publicados tanto na Europa como no Brasil. Foi por reconhecimento a esse esforço, que Carlos von Koseritz $^{38}$ e Henry Lange ${ }^{39}$ editaram a obra póstuma a ser analisada, e que contém os primeiros registros explícitos sobre o buriti na metade norte do Rio Grande do Sul.

Em "passeios e cavalgadas pela margem esquerda do rio Turvo", no noroeste do estado, Max Beschoren registrou a alternância de "verdejantes gramados" com "pequenas matas de variadas formas de vegetação", como os "bosques de timbó" e de "buriti", espécie descrita como "magnífica palmeira em forma de leque". ${ }^{40}$ Ao caracterizar a "vegetação do Alto Uruguai”, o autor volta a referir-se à árvore - e quase nos mesmos termos -, acrescentando, todavia, outras duas Arecáceas à flora regional: a "guariganga" e uma espécie de butiá, descrita como "como palmeira anã", que "aparece nos campos". ${ }^{41}$ Embora alheio ao tema do presente artigo, não custa tecer breves comentários sobre essas palmeiras.

${ }^{38}$ Filho do barão Karl von Koseritz, Carlos von Koseritz (1830-1890) veio ao Brasil em 1851 para integrar o contingente de militares alemães (Brummers) contratados para lutar na guerra contra Oribe e Rosas. Após deserção, Carlos von Koseritz atuou no jornalismo, em Porto Alegre, destacando-se, ainda, como político, empresário e escritor.

${ }^{39}$ Cartógrafo alemão (1821-1893), autor de numerosos artigos publicados em jornal, bem como mapas e livros sobre o Rio Grande do Sul. De sua bibliografia destacase "Südbrasilien - Die Provinzen São Pedro do Rio Grande do Sul, Santa Catharina und Paraná mit Rücksicht auf die deutsche Kolonisation”, editada em Leipzig (1885).

${ }^{40}$ BESCHOREN, M. Impressões de viagem na província do Rio Grande do Sul. Porto Alegre: Martins Livreiro, 1989. p. 60.

${ }^{41}$ BESCHOREN, M., 1989, Op. cit., p. 166-167. 
O nome comum "guariganga" ou "guaricana" se aplica a Geonoma schottiana Mart. ${ }^{42}$, espécie "com ampla distribuição no Brasil", embora restrita, no Rio Grande do Sul, à "região litorânea, desde Torres até o município de Rio Grande". ${ }^{43}$ Para o estado de Santa Catarina $^{44}$, a espécie consta como nativa somente na região fitogeográfica da "mata pluvial da Encosta Atlântica", causando estranheza a indicação do engenheiro do século dezenove para a floresta do Alto Uruguai. Mesmo contestando a literatura botânica disponível, a referência do meticuloso alemão é merecedora de crédito, até prova em contrário, cabendo investigação mais detalhada, tanto na natureza como na literatura, com vistas à confirmar (ou descartar) uma pretérita disjunção dessa espécie no Alto Uruguai.

A respeito da "palmeira anã" mencionada por Beschoren, trata-se, provavelmente, da primeira referência literária a Butia exilata Deble \& Marchiori, espécie descrita apenas em 2011 - e para Ronda Alta e os arredores do "Parque Estadual de Rondinha" -, ao norte de Passo Fun$\mathrm{do}^{45}$.

\section{REFERÊNCIAS BIBLIOGRÁFICAS}

ASSIS-BRASIL, L.A. de. Figura na sombra. Porto Alegre: L\&PM, 2012. 264 p.

AVÉ-LALLEMANT, R. Viagem pelo sul do Brasil no ano de 1858. Rio de Janeiro: Ministério da Educação e Cultura; Instituto Nacional do Livro, 1953. Primeira parte, 398 p. (Tradução de Teodoro Cabral).

${ }^{42}$ REITZ, R.; KLEIN, R.M.; REIS, A. Projeto Madeira de Santa Catarina. Sellowia, Itajaí, 1978, p. 51.

${ }^{43}$ SOARES, K.P.; LONGHI, S.J.; WITECK NETO, L.; ASSIS, L.C. Palmeiras (Arecaceae) no Rio Grande do Sul, Brasil. Rodriguesia, Rio de Janeiro, v. 65, n. 1, 2014, p. 127.

${ }^{44}$ REITZ, R.; KLEIN, R.M.; REIS, A. Projeto Madeira de Santa Catarina. Sellowia, Itajaí, 1978, p. 51.

${ }^{45}$ DEBLE, L.P.; MARCHIORI, J.N.C.; ALVES, F. da S.; OLIVEIRA-DEBLE, A.S. de. Survey on Butia (Becc.) Becc. (Arecaceae) from Rio Grande do Sul State (Brazil). Balduinia, Santa Maria, n. 30, 2011, p. 5-9.
BELL, S. A life in shadow. Aimé Bonpland in southern South America, 1817-1858. Stanford: Stanford University Press, 2010. 320 p.

BESCHOREN, M. Impressões de viagem na província do Rio Grande do Sul. Porto Alegre: Martins Livreiro, 1989. 200 p. (Tradução de Ernestine Marie Bergmann e Wiro Rauber).

BONPLAND, A. Archives inédites. Buenos Aires: Jacobo Peuser Ltda., 1924. Tomo 2. (edição facsimilar do original manuscrito). s.p.

BONPLAND, A. Journal Voyage de Sn. Borja a la Cierra y a Porto Alegre. Porto Alegre; Instituto de Biociências, Departamento de Botânica; Paris: Centre Nationale de la Recherche Scientifique, 1978. 175p.

CANO, A.; PERRET, M.; STAUFFER, F.W. A revision of the genus Trithrinax (Cryosophileae, Coryphoideae, Arecaceae). Phytotaxa, v. 136, n. 1, p. 1-53, 2013.

CARVALHO, M.T. de. Nobiliário Sul-Riograndense. Porto Alegre: Livraria do Globo, 1937. 371 p.

DEBLE, L.P.; MARCHIORI, J.N.C.; ALVES, F. da S.; OLIVEIRA-DEBLE, A.S. de. Survey on Butia (Becc.) Becc. (Arecaceae) from Rio Grande do Sul State, Brazil. Balduinia, Santa Maria, n. 30, p. 3-24, 2011.

FARIA, O.A. de. Diccionário Geográphico, Histórico e Estatístico do Estado do Rio Grande do Sul. Porto Alegre: Livraria do Globo, 1914. 423 p. ( $2^{\mathrm{a}}$. edição).

HENIS, T.X. Diario historico de la rebelion y guerra de los pueblos guaranis, situados en la costa oriental del rio Uruguay, del año 1754. Buenos Aires: Editorial Plus Ultra, 1970. v. 5, p. 449-577.

LORENZI, H.; SOUZA, H.M. de; COSTA, J.T. de M.; CERQUEIRA, L.S.C. de; FERREIRA, E. Palmeiras brasileiras e exóticas cultivadas. Nova Odessa: Instituto Plantarum, 2004. p. 239.

LORENZI, H.; NOBLICK, L.R.; KAHN, F.; FERREIRA, E. Flora Brasileira: Arecaceae. Nova Odessa: Instituto Plantarum, 2010. p. 361364.

MARCHIORI, J.N.C.; ALVES, F. da S. A histórica estância de Santiago, em Saint-Hilaire e outros clássicos da literatura sulina. Balduinia, Santa Maria, n. 27, p. 15-19, 2011.

MATTOS, J.R. Palmeiras do Rio Grande do Sul. Roessleria, Porto Alegre, v. 1, n. 1, p. 5-94, 1977. 
REITZ, R. Palmeiras. In: REITZ, R. Flora Ilustrada Catarinense. Itajaí: Herbário Barbosa Rodrigues, 1974. $189 \mathrm{p}$.

REITZ, R.; KLEIN, R.M.; REIS, A. Projeto Madeira de Santa Catarina. Sellowia, Itajaí, p. 1-320, 1978.

SAINT-HILAIRE, A. de. Viagem a Curitiba e província de Santa Catarina. Belo Horizonte: Editora Itatiaia, 1978. 209 p.

SAINT-HILAIRE, A. de. Viagem ao Rio Grande do Sul. Porto Alegre: ERUS; Martins Livreiro, 1987. $496 \mathrm{p}$.

SALDANHA, J. de. Diário Resumido e Histórico. Anais da Biblioteca Nacional, Rio de Janeiro, v. 51, p. 137-301, 1938.
SOARES, K.P.; LONGHI, S.J. Uma nova espécie de Butia (Becc.) Becc. (Arecaceae) para o Rio Grande do Sul, Brasil. Ciência Florestal, Santa Maria, v. 21, n. 2, p. 203-208, 2011.

SOARES, K.P.; LONGHI, S.J.; WITECK NETO, L; ASSIS, L.C. de. Palmeiras (Arecaceae) no Rio Grande do Sul, Brasil. Rodriguésia, Rio de Janeiro, v. 65, n. 1, p. 113-139, 2014.

SÜHS, R.B.; PUTZKE, J. Nota sobre a ocorrência de uma população de Trithrinax brasiliensis Martius (Arecaceae) no vale do rio Pardo, Rio Grande do Sul, Brasil. Pesquisas, Botânica, São Leopoldo, n. 61, p. 330332, 2010. 